\title{
Positive Mood and Susceptibility to False Advertising
}

\author{
Kathryn A. LaTour, University of lowa \\ Michael S. LaTour, University of Mississippi
}

This paper examines the impact of mood on consumers' implicit and explicit responses to false advertising. In our first experiment, we find that those consumers in a positive (versus a negative or neutral) mood state are more likely to notice the false information in the advertising, but paradoxically, are also likely to develop positive feelings toward the brand. In that experiment, we used both a hedonic brand (Disney) and a hedonic/emotional ad (autobiographical). In our second experiment, we extend the ad stimulus context beyond Disney to Wendy's to more readily facilitate autobiographical versus informational manipulations. We find that, indeed, the hedonic advertising execution (autobiographical vis-àvis informational) is associated with more elaborate processing (but only for those in a positive mood). The observed positive affect transfer continued, however, despite the greater detection of the false information in the positive mood condition. We propose that the negative feelings toward the ad associated with detecting the false information are momentary and are replaced by positive feelings toward the brand that are engendered by positive mood and the advertising, as suggested by the synapse model of memory. Our third experiment varies the timing of our measures to investigate this proposition and finds that timing does matter. We conclude with a discussion of the implications of the findings for research on mood, deceptive advertising, and implicit versus explicit effects of advertising response.

Few researchers would argue against the impact that positive mood has on consumer behavior. In fact, the pervasiveness of this impact over the last several decades of research led Petty et al. (1993) to quote social psychologist McGuire as to the state of this issue:

Persuasive impact is greater if the person is in a happy, benevolent mood when the message comes, noshing on peanuts and soda, watching a good program, and with pleasant musical background, an appropriately scented other, a smile on one's face, nodding one's dead, or relaxed in posture. $(1985$, p. 285) 
From the above summary, it seems all marketers need to do is get consumers in a happy mood and they will be amiable to advertising tactics. To some degree, this "main effect" of positive mood has been found in the advertising domain, where advertising received under a positive affect has been found to be remembered better (e.g., Goldberg and Corn 1987) and rated more favorably (e.g.. Kamins, Marks, and Skinner 1991; Mathur and Chattopadhyay 1991) than if received under a more neutral or negative mood. However, why this occurs and the cognitive mechanisms involved in this process have been the center of debate. Several views dominate: One group finds that consumers in a positive mood are mindless, accepting of even low-quality arguments in advertising (Batra and Stayman 1990; Bless et al. 1990; Mackie and Worth 1989; Stayman and Batra 1991; Worth and Mackie 1987), whereas another group finds that those in a positive mood are more flexible, creative, and efficient in their processing, and thus create more elaborative networks of association (Isen 1984; Lee and Sternthal 1999). Still another view suggests that the positive mood environment is an effective one in which to place advertising not because it alters how elaborately consumers process the advertising information itself, but rather due to the affect transfer from environment to advertised product that occurs on a more subconscious level (Goldberg and Gorn 1987).

Past persuasion research has taken an "either/or" position on how mood affects how people process advertising; positing the mood state causes consumers either to process at a very superficial level where they become affected by extraneous cues or at a very deep level and are affected by logically based arguments. Now newer research in psychology and marketing acknowledges that people can have coming ling thought processes, that is, they can be happy and sad at the same time, or on one level, they might say they dislike an advertisement, but on another level, have a positive feeling toward the advertised brand (see Zaltman 2003). While at times these processes may occur together and reveal similar associations (Brunei, Tietje, and Greenwald 2004), at other times, these processes may not. It is this disconnect that presents interesting opportunities for advertising researchers seeking alternative methods to measure advertising response.

Suggestion is defined as a "process of communication during which one or more persons cause one or more individuals to change (without critical response) their judgments, opinions, attitudes"(Eysenck, Arnold, and Meili 1975, p. 1077). While there are cases where being influenced by an advertisement is not a bad thing (i.e., informational ads), our interest involves the times when consumers are influenced when they shouldn't be-either because the ad information was incorrect or because some other external source (i.e., television program) unknowingly affected their feelings regarding the advertised brand. We conceptualize mood as influencing response to an advertisement as 
occurring on two levels: explicitly, where the mood state elicited from the programming leads to more/less consumer acceptance of the information in the advertising message (regardless of its validity), and implicitly, where consumers subconsciously transfer their mood from the environment (in our case, video) toward the advertised brand.

\section{Conceptual Background}

\section{False Advertising and Cognitive Response}

According to Skurnik et al. (2005), due to the vast amount of information available to consumers, varying on levels of credibility, one of the most important decisions a consumer makes is whether the information he or she encounters is true or false. The "Spinozan processor" explanation of belief formation posits that people automatically encode new information as true, if only for a moment (Gilbert 1991). Only if the person is involved in subsequent cognitive effort does he or she "unbelieve" that information which is not true. When a person's cognitive capacity is taxed, he or she has difficulty rejecting false propositions.

Advertising research on consumers' acceptance of false or misleading advertising stems from early research in the 1970s on deceptive advertising (Olson and Dover 1978). Much of that research resulted in definitions of deception and had implications for Federal Trade Commission (FTC) policy and regulations. Our interest in that research, however, lies with the observation that consumers will accept information from advertising without critical response. In the Olson and Dover study (1978), for instance, they provided consumers with a bitter-tasting coffee and later an advertisement suggesting that the coffee had "no bitterness." Those researchers defined deception by the fact that people felt that the bitter coffee was much less so after seeing the advertisement.

More than 20 years later, Braun (1999) used a similar research procedure: She had participants taste a bitter, salty, watered-down orange juice and exposed them to an advertisement suggesting that juice was "fresh, sweet, flavorful." As did Olson and Dover (1978), Braun observed that consumers accepted the misleading advertisements and had more favorable attitudes toward the juice than those who did not receive any advertisement. Because product quality is subjective (i.e., one person may like bitter coffee or tart juice, whereas another might not), the misleading advertisements may not necessarily lead to the creation of the false beliefs identified in those studies. Therefore, Braun and her colleagues have begun incorporating false information in the advertisement to see whether consumers accept that information. For instance, an ad suggesting that everyone meets Bugs Bunny at Disneyland is 
unequivocally false-he is a Warner Bros, character and would never be at a Disney resort. Therefore, if consumers, after seeing the ad, report having memories where they met Bugs Bunny at Disneyland, then one can conclude that this false memory/ belief occurred because of the advertising exposure.

There have been many demonstrations of the advertising misinformation effect (e.g., Braun and Loftus 1998; Braun, Ellis, and Loftus 2001; Braun-LaTour, Grinley, and Loftus 2006; Braun-LaTour et al. 2004). Little is known about potential moderators that influence susceptibility, however. Individual characteristics such as gender and intelligence do not appear to correlate well with susceptibility (Schumaker 1991). In fact, persuasion researchers suggest that perhaps instead of looking for "who," we might be better off looking for "when" consumers are more accepting of advertising information. A number of researchers argue that the susceptibility process depends mainly on situational factors (Schumaker 1991). Mood is one situational context that advertisers can greatly influence. Advertisers can, for instance, choose the programming or magazine or newspaper, or even Internet site, by the mood elicited by that medium's content. Mood and memory are intertwined, so a natural progression of the advertising literature is to determine how (and if) mood state influences one's susceptibility to false advertising.

There has been some research on ways consumers can inoculate themselves from falling susceptible to advertising suggestion: To avoid being misled by deceptive advertising, a consumer has to process the new information in a deep manner (Johar 1995), so that they are able to detect the false claim. Researchers investigating advertising deception find that anything that leads to consumers taking a more rational approach that would lead to more skepticism in the advertising results in less deception (Lord and Kim 1995). Researchers looking at false advertising or information find similar effects: When the false information is blatant or noticed by participants, there is much less susceptibility (Braun-LaTour et al. 2004; Loftus 1979; Tousignant, Hall, and Loftus 1986).

\section{Mood and Cognitive Processing}

As mentioned in our introduction, the traditional view is that consumers would be less persuaded by an advertisement in a sad mood than in a positive mood (Aylesworth and Mackcnzie 1998; Batra and Stayman 1990; Bless et al. 1996; Kuykendall and Keating 1990; Mackie and Worth 1989; Schwarz and Bless 1991; Worth and Mackie 1987). That research stream would suggest that positive mood makes the consumer less critical, and thus might make the consumer more susceptible co false advertising suggestion (e.g., Bless et al. 1990). The work of Batra and Stayman (1990) and Stayman and 
Batra (1991) with advertising stimuli supported the view that positive mood leads consumers to be influenced by peripheral or weak information, therefore exhibiting more "heuristic" processing.

More recent research suggests, however, that people actually may be better processors of information in a positive mood. Isen and her colleagues have conducted the most thorough research in the area of positive mood and its role in information processing (though the majority of this research compares positive to neutral rather than to negative/sad moods). These researchers have shown that positive mood functions to improve integration of information, problem solving, decision making, and cognitive organization in a wide variety of settings (see Estrada, Isen, and Young 1997). The induction of a positive mood context (usually through a small gift but through other means as well) has been shown to improve creative problem solving (Isen, Daubman, and Nowicki 1987), lead to taster and more accurate decision making (Estrada, Isen, and Young 1997), and more flexible categorization (Isen and Daubman 1984).

Positive mood is thought to enhance decision making because it fosters cognitive elaboration (Isen, Daubman, and Nowicki 1987) and relational processing (Isen 1993; Lee and Sternthal 1999). Relational processing involves encoding items in relation to other concepts in memory. Researchers believe that negative mood may lead to better item-specific processing, but at the expense of relational processing (Arndt and Reder 2003). Item-specific processing involves encoding items by their features, elements, and distinctive qualities.

Particularly relevant to the false advertising context is the finding that those in a positive mood are more responsive to instructions to find similarities or differences in a list of products (Murray et al. 1990). By extension, positive mood might help consumers notice discrepancies in the false advertising information. In addition, the greater elaboration under positive mood should lead consumers to scrutinize the false advertising information to a greater degree and detect the false information more readily than other mood states. Consistent with this view, Aylesworth and MacKcnzie (1998) found that advertisements placed in programs that induce negative moods are processed less systematically than ones that induce positive moods. Therefore, we propose the following hypothesis regarding mood's influence on the more explicit effects of false advertising susceptibility:

Hypothesis 1: Positive mood will foster tons timers' elaboration and relational processing of the false advertising, and this deeper processing should lead to more detection of the false information \{compared to neutral of negative mood participants). This will result It in positive mood participants rejecting the false information I more so than their neutral or negative mood counterparts) in making brand-related judgments. 


\section{Mood and Implicit Effects}

That mood can have both automatic and more controlled effects on advertising acceptance maps onto the implicit versus explicit distinction made by psychologists. Mood, for instance, can exert a direct effect on the type of processing strategy employed by consumers as they view the ad (which was discussed in the previous section). Mood can also have indirect effects on consumer judgments, as through affect priming or mood congruence in judgments. This distinction is based on the level of consciousness in the memory task. Explicit memory generally refers to what is top-of-mind and involves having the consumer think back about a prior episode and intentionally attempt to access that information (Schacter 1996; Shapiro and Krishnan 2001), while implicit memory refers to information that is below one's conscious awareness but can greatly influence decision making nonetheless (Schacter 1996).

The majority of research on advertising susceptibility has employed measures that would be considered explicit. By definition, to be misled by a particular advertisement means that any resulting false beliefs or memories are a result of that particular episode (Olson and Dover 1978). The effects of receiving false advertising in different mood contexts have other layers of effects, however. Mood can also influence consumers' susceptibility to a false advertising message through a more peripheral route, where they report "feeling more/less favorable" about the advertised brand because of their mood. The more automatic effect of mood, called "affect priming," has been the major mechanism responsible for mood-congruent judgment effects (Forgas 2001). Goldberg and Gorn (1987) say that both the transfer of affect as a function of temporal association and the priming of similarly toned material in memory can be viewed as automatic processes. Many researchers find that explicit and implicit measures do not necessarily correspond (e.g., Zaltman 2003). We therefore pose the following hypothesis:

Hypothesis 2: The mood context will transfer to feelings about the advertised brand through a peripheral route resulting in affect transfer. Those participants in a positive mood will feel more positive about the brand than those who are in a negative or neutral mood (as measured through our implicit measure).

\section{Dependent Measures}

The advertising misinformation paradigm was chosen to measure consumers' cognitive response to the false advertising (e.g., Braun-LaTour et al. 2004). In that paradigm, consumers are shown an advertisement that contains a false cue and are asked to write their thoughts and feelings 
about the ad. Those who notice the false information within the advertisement are labeled "detectors" and are indicative of consumers who have not succumbed to the falsity at encoding (Braun-LaTour et al. 2004). In past research, the explicit measure of acceptance of the false information was measured by whether or not participants "remembered" the false cue as being part of their own childhood experience (e.g., Braun-LaTour et al. 2004). In our studies, we measure the acceptance of the false information by assessing whether consumers integrate the false information in later categorization judgments.

The Implicit Association Test (IAT) was chosen to measure affect transfer between mood and the advertised brand. This test was developed to measure the degree to which attitude constructs can operate subconsciously or implicitly (Greenwald and Banaji 1995). The IAT is capable of measuring differences in association between target concepts (e.g., Disney or other theme resorts) and evaluative attributes (e.g., good or bad). The basic assumption is that consumers should find it easier to make the same behavioral response to concepts that are associated than to those not associated. More specifically, it relies on a response latency indicator obtained in the process of pairing an attitude concept (brand) with an evaluative attribute (good or bad). In computerized versions of this task (as used here), the pairing is achieved by assigning a keyboard key (e.g., "e") to be pressed in response to two linked categories, such as Disney and good, while another keyboard key (e.g., "i") is used for the other pair, that is, "other" and bad. There are many demonstrations that the IAT effects are large, robust, and subject to test-retest reliability (e.g., Greenwald and Nosek 2001). The IAT has been used by marketers to measure associations between brands and implicit attitudes (Brunei, Tietje, and Greenwald 2004; Gibson 2008; Maison, Greenwald, and Bruin 2001).

\section{Experiment 1}

The primary interest in this first experiment was to determine which mood state would lead to the least/most susceptibility to the false advertising. We code participant's responses to the advertising to determine what type of processing they employed when evaluating the ad-superficial, relational, item-specific, or both relational and item-specific-and whether or not they notice the false Bugs Bunny information in the ad. We also look at whether participants embrace the false information in later categorization judgments as a means to measure their acceptance of the false information. We use the IAT to assess how they implicitly feel about the advertised brand to determine whether there is any affect transfer from the mood-inducing videos. 


\section{Method}

Participants

One hundred forty undergraduates (79 female, 61 male) participated in this study for course credit. The average age was 23 .

Design

Participants were assigned to either a false ad group or a control ad group (for baseline measures). The advertisements used by Braun, Ellis, and Loftus (2001) were adapted for our study. The false ad contains both a picture and false verbal reference to Bugs Bunny at Disney World. The "true" ad is exactly the same, but contains a picture of Mickey Mouse and reference to him within the text. The ad encourages the reader to take a trip back to his or her childhood and provides some cues to help bring them back. The false pan of the text reads: "With the song 'It's a Small World' in your mind, you ventured back to your hotel to rest up for another day. Just then, you spotted one of the characters, looks like Bugs Bunny! He waved you over. Adrenaline rushed through you and somehow you were able to move your feet in his direction. He shook your hand. The perfect end to a perfect day." Later in the ad, the text says: "Memories like yours are what makes Disney so special...All of us have had the opportunity to meet our favorite characters up close..." The implication is that Bugs Bunny is one of those favorite Disney characters and all children have had the opportunity to meet him during their childhood visits to the park.

Procedure

Participants came to a computer lab room and watched a 20-minute video: the positive mood induction group saw a comedy routine by Bill Cosby and a clip from Jim Carrey's movie Liar, Liar; ${ }^{1}$ the neutral mood induction group viewed a documentary about Einstein ${ }^{2}$ and the negative (sad) mood induction group viewed a clip from the movie Steel Magnolias, taken from a critical scene where Julia Roberts's character dies and her mother, played by Sally Field, has a breakdown at the funeral. These mood induction videos had been pretested to ensure the proper mood state (Filopowicz 2000; Puccinelli 2000). Note that our negative mood state could be best labeled "sad" and our positive state "happy." Following the video, a questionnaire was passed out. On the first page, participants were asked to fill out the Mood Short Report form (per Peterson and Sauber 1983) as a manipulation check. The Disney ad was then passed out, and the participants were asked to provide written feedback on it. Note 
that we did not instruct them to notice anything wrong with the ad; we were interested in whether they would notice the false information without being directed to do so. Afterward, they completed a distraction task to clear short-term memory. Participants then tilled out demographic information and then proceeded to the IAT.

The IAT involves grouping words into categories. Words appear on the screen and the participant's job is to indicate into which category the word belongs by pressing a certain key. The key categories tested here were whether a word was "good" or "bad," and whether the word was associated with Disney or another theme resort. The good/bad word choices came from past IAT tests (e.g., Greenwald, McGhee, and Schwartz 1998). The Disney category consisted of the following words: Euro Disney, Mickey Mouse, Space Mountain, Goofy, Disneyland, Peter Pan, Walt Disney World, and Epcot. The non-Disney category had the following words: Universal Studios, Sea World, Sylvester, Busch Gardens, Six Flags, Visionland, Daffy Duck, and Tweety. In the critical trials, both the good/ bad words and the Disney/"other" words appear randomly on screen. The categorization involves grouping Disney/good together and "other'/bad together (by pressing the related keys). The other critical trial had participants classify the words, but the categories were switched to Disney/bad and "other"/ good. The idea is that if the categories are similar (such as Disney/good) participants will be faster in categorizing those words than when the categories are more discrepant (such as Disney/bad). The differential speed required to complete these two types of pairings, that is the relative ease of pairing Disney + good and "other" + bad, is interpreted as a measure of the strength of the implicit attitude.

There were images of Bugs Bunny within that categorization task. Our interest was whether participants would include him as being part of the Disney category (thus incorporating the false information in their judgments). We specifically look to see whether consumers incorrectly categorize Bugs Bunny as belonging to the Disney category or correctly belonging to other theme parks (he appears at Six Flags resorts). Bugs Bunny appeared six times within the task. Unlike other words, which triggered an " $x$ " on screen when there was an error, the computer allowed either response for Bugs Bunny.

\section{Measures}

As a mood manipulation check, we used the Mood Short Form (Peterson and Sauber 1983) where, after seeing the video, participants reported on a seven-point scale how much they agreed /disagreed with the following four statements: "Currently I am in a good mood"; "After seeing the video, I feel very cheerful"; "For some reason I am not very comfortable right now"; "At this moment 1 feel edgy or irritable." The third and fourth scales arc reverse coded, so that higher values indicate a more 
positive mood state. The participants wrote feedback to the false (or true) advertising in an open-ended fashion. They then filled out background questions, age, gender, past visitation to Disney resorts, and whether they were right- or left-handed (there was no significant difference on these measures across groups).

We looked at the IAT effect across groups, which is the difference in the average response times between Disney－ bad/"'other"-good and Disney-good/"other"-bad. We also counted the number of times the participant had classified Bugs Bunny as belonging to the Disney category, which is our measure of how much they integrated the false information into their judgments. As in all potential deception studies, where there might be "hypothesis guessing" that leads to demand effects, we included a question at the end of the study where they were given the opportunity to guess the purpose of our study. No one correctly concluded that we were interested in whether the mood-inducing video caused them to notice/ not notice the false Bugs Bunny information in the ad.

\section{$\underline{\text { Results }}$}

\section{Mood Manipulation Check}

Our first order of interest was whether or not the induction video produced the desired mood. After finding that the four mood items loaded on one factor with Cronbach's ( $\alpha$ of .9 (after two had been reverse-coded), they were averaged together to form an overall mood index. The groups were distinctly different in the predicted direction (higher values $=$ more positive mood): $M=8.8$ for the false $\mathrm{ad} /$ positive mood, $M=5.7$ for control ad/positive mood, $M=3.9$ for false ad/neutral mood, $M=3.9$ for control ad/neutral, $M=3.2$ for false ad/negative mood, and $M=3.1$ for control ad/negative mood; significant at $F(5,139)=38.3$, with post hoc tests finding each mood group to be significantly different from each other (using Tukey $p=.05$ ).

\section{Coding Procedure}

Two independent judges coded participants' reactions to the ads. They coded the number of words used in response to the ad and whether or not participants noticed that Bugs Bunny did not belong in a Disney ad. In addition, they coded the processing strategy indicated by a participant's written response to die ad, resulting in these four categories: superficial (where they either wrote nothing in response to the ad, or wrote something unrelated to the ad, such as "I am bored" or "This doesn't relate to me"); item-specific (where they wrote specifically about the information presented in the ad, or commented on the execution, writing style, use of colors); relational (where they related the 
ad information to either their own past experience at a Disney resort or general knowledge about Disney); or both (which meant they wrote about specific ad details as well as relating their own experience). The coders had no knowledge of the experimental hypotheses. Their interrater reliability was .88 , and disputes were settled by a third party.

\section{Advertising Response}

Our primary interest was in how participants responded to the false advertising; the control condition was primarily to get baseline measures of the acceptance of the false information (e.g., BraunLaTour et al. 2004), and therefore our analysis focuses on the false advertising conditions. We found that those in the positive mood condition wrote significantly more than the other two conditions in response to the false advertising (see Table 1 for the means). The overall model was significant at $\chi^{2}(n=$ $81)=33.97, p<.0001$; the positive mood condition participants wrote significantly more than the neutral condition participants, $\chi^{2}(n=51)=19.23, p<.0001$, and also significantly more than the negative condition participants, $\left.\chi^{2} n=55\right)=22.15, p<.0001$. We also found that the mood influenced how they reacted to the false information in the advertising. Those who scrutinize the ad information to a greater degree at encoding will be more likely to notice the discrepancy of Bugs Bunny appearing in the Disney ad. In this study, we found such scrutinization more often in the positive mood than either the neutral or negative groups, which supports the HI prediction that positive mood would enhance processing of the false information.

This greater detection in the positive mood condition seemed to be due to the processing strategy: Those in a positive mood were more likely to employ both relational and item-specific processing compared with the other mood conditions. An example of a participant using both of these strategies (and typical of those in the positive mood condition) follows: "The ad said you got to meet Bugs Bunny. That threw me off-Bugs Bunny is a Warner Bros, character and I never met him at a Disney park. My Disney vacations were some of the best childhood experiences I had, very happy times. But this ad put me off-wasn't able to relate to the Bugs Bunny part."

Most of the negative (56\%) and the neutral (53\%) participants used only a relational processing strategy, perhaps due to the autobiographical nature of the ad ( $16 \%$ of positive mood participants used only this type of strategy). For instance, one participant in the negative mood condition said: "This ad made me think of my family vacation at Disney World. I loved the rides. It is truly a fantasyland for kids. I hope to take my own kids there someday (when I have them)." 
There was some item specific-only processing in the neutral (35\%) and negative mood conditions (30\%), but not much of this type of processing in the positive condition (12\%). An example of item-specific processing from the neutral condition follows: "I didn't like the colors. The graphics seemed very unprofessional to me." Therefore, it appears that neither item-specific processing nor relational processing is enough for detection; both types are needed in order for one to notice the false information.

Acceptance of the False Information

Based on prior research (e.g., Braun-LaTour et al. 2004), we suspected that participants would not readily associate Bugs Bunny with Disney without receiving the reference in the false advertising. However, because participants are told to complete the IAT quickly and that "some mistakes are OK," we wanted to get a baseline for the amount of errors that might occur regardless of the false advertising. The control results appear in Table 2 in parentheses, and there were no significant differences across mood conditions in the classifying of Bugs Bunny as belonging to Disney. When mood was induced, however, the positive mood participants were less likely than negative and neutral mood participants to make that error; the model was significant at $F(2,78)=6.45 p<01$ (see Table 2 for the means). Post hoc tests using the Tukey approach found the positive condition to be significantly different from the other two conditions $(p<.05)$.

\section{Implicit Association Task}

We were interested in finding out whether the mood induction would transfer to affect associated with Disney as revealed through our implicit measure, per Hypothesis 2. Half the participants received these critical trials third and fourth in sequence; the other half, seventh and eighth. After finding no significant difference in IAT effect for these presentation orders (nor any differences between right- and left-handers), the data were combined (see the means in Table 2). Note that the "true" and "false" ad conditions did not differ significantly from one another. All conditions had favorable implicit attitudes toward Disney, but the positive mood condition more so; the model was significant at $F(5$, 139 ) $=4.32, p=.001$ (and mood was the only significant factor, $\mathrm{F}[2,139]=10.65, p<.0001$ ). Post hoc tests found each mood condition to be significantly different from each other. 


\section{Relationships between Measures}

We expected that the IAT and the acceptance of the false information measure would not be related, and that was found, $r=-.1$ (because the IAT is an implicit measure, the acceptance of the false information is an explicit measure). The Bugs detectors and the acceptance of the false information in the categorization task were negatively related, $r=-.52$, meaning that if one detects the false information, one is less likely to accept that information in later judgments. The best predictor of whether one detects is if they are using both item-specific and relational processing when they process the false advertisement, $r=.41$.

TABLE I

Response to the False Advertising

\begin{tabular}{|c|c|c|c|c|c|c|c|}
\hline & \multicolumn{2}{|c|}{ Open-ended response } & \multicolumn{4}{|c|}{ Processing strategy } & \multirow{2}{*}{$\begin{array}{c}\text { Attitude scale } \\
\text { Attitude } \\
\text { toward } \\
\text { the ad }\end{array}$} \\
\hline & $\begin{array}{l}\text { No. of } \\
\text { words }\end{array}$ & Detector & Superficial & $\begin{array}{l}\text { Item- } \\
\text { specific }\end{array}$ & Relational & Both & \\
\hline \multicolumn{8}{|l|}{ Experiment I* } \\
\hline Positive & $64(55)$ & $50 \%$ & $2(4 \%)$ & $12(15 \%)$ & $16(20 \%)$ & $70(50 \%)$ & - \\
\hline Neutral & $39(31)$ & $19 \%$ & $1(10 \%)$ & $35(21 \%)$ & $53(53 \%)$ & $11(15 \%)$ & - \\
\hline Negative & $48(42)$ & $23 \%$ & $8(5 \%)$ & $30(35 \%)$ & $56(50 \%)$ & $6(10 \%)$ & - \\
\hline \multicolumn{8}{|l|}{ Experiment 2} \\
\hline \multicolumn{8}{|l|}{ Autobiographical } \\
\hline Positive & 37 & $68 \%$ & $4 \%$ & $8 \%$ & $12 \%$ & $76 \%$ & 4.5 \\
\hline Neutral & 31 & $16 \%$ & $20 \%$ & $56 \%$ & $20 \%$ & $4 \%$ & 6.5 \\
\hline Negative & 34 & $12 \%$ & $4 \%$ & $48 \%$ & $40 \%$ & $12 \%$ & 6.0 \\
\hline \multicolumn{8}{|l|}{ Informational } \\
\hline Positive & 37 & $12 \%$ & $16 \%$ & $72 \%$ & $4 \%$ & $8 \%$ & 6.0 \\
\hline Neutral & 24 & $24 \%$ & $16 \%$ & $64 \%$ & $12 \%$ & $8 \%$ & 6.0 \\
\hline Negative & 34 & $4 \%$ & $24 \%$ & $72 \%$ & $0 \%$ & $4 \%$ & 6.2 \\
\hline \multicolumn{8}{|l|}{ Experiment 3} \\
\hline Ad response, immediate-IAT immediate & 32 & $68 \%$ & $8 \%$ & $16 \%$ & $0 \%$ & $76 \%$ & 5.1 \\
\hline Ad response, immediate-IAT delay & 30 & $63 \%$ & $3 \%$ & $20 \%$ & $7 \%$ & $67 \%$ & 5.0 \\
\hline Ad response, delay-IAT immediate & 31 & $24 \%$ & $0 \%$ & $52 \%$ & $20 \%$ & $28 \%$ & 5.7 \\
\hline Ad response, delay-IAT delay & 31 & $27 \%$ & $5 \%$ & $44 \%$ & $28 \%$ & $11 \%$ & 5.8 \\
\hline
\end{tabular}


TABLE 2

Consequences of the False Advertising

\begin{tabular}{|c|c|c|}
\hline & $\begin{array}{c}\text { Acceptance } \\
\text { of deception } \\
\text { (no. of times } \\
\text { incorrectly } \\
\text { categorized; } \\
\text { maximum 6) }\end{array}$ & $\begin{array}{c}\text { IAT } \\
\text { (in ms) }\end{array}$ \\
\hline \multicolumn{3}{|c|}{ Experiment I } \\
\hline Positive & $1.2(1.4)^{*}$ & $387(404)$ \\
\hline Neutral & $3.2(1.3)$ & $264(258)$ \\
\hline Negative & $3.2(1.5)$ & $243(223)$ \\
\hline \multicolumn{3}{|c|}{ Experiment 2} \\
\hline \multicolumn{3}{|c|}{ Autobiographical } \\
\hline Positive & .36 & 335 \\
\hline Neutral & 2.4 & 180 \\
\hline Negative & 2.4 & 112 \\
\hline \multicolumn{3}{|l|}{ Informational } \\
\hline Positive & 2.3 & 323 \\
\hline Neutral & 2.5 & 156 \\
\hline Negative & 3.8 & 24 \\
\hline \multicolumn{3}{|c|}{ Experiment 3} \\
\hline Immediate & 1.9 & 107 \\
\hline Delay & 2.9 & 276 \\
\hline \multicolumn{3}{|c|}{ Note: IAT = Implicit Association Test. } \\
\hline \multicolumn{3}{|c|}{$\begin{array}{l}\text { * Baseline measures with the "true" control ad appear in parentheses for } \\
\text { Experiment } 1 \text {. As a point of comparison, participants miscategorized } \\
\text { Daffy Duck on average } 1.4 \text { times. }\end{array}$} \\
\hline
\end{tabular}

\section{$\underline{\text { Discussion }}$}

The purpose of this study was to see in which mood state participants would show the most/least susceptibility to the false advertising. Consistent with Hypothesis 1, we found that the positive mood induction led to deeper processing, where participants were more likely CO Switch between item-specific and relational processing. To detect and withstand potential deception, one needs to activate both the ad information and one's own personal experience in working memory. This cognitive flexibility was enhanced by the positive mood induction and is consistent with research finding that a positive mood allows people to notice both the similarities and differences in stimuli (Murray et al. 1990). This finding also supports the view that positive mood can enhance rather than detract from processing (which is contrary to the dominant view in advertising that positive mood leads to less careful processing).

In terms of how consumers felt about the advertised brand, consistent with Hypothesis 2, we found mood congruence on our implicit measure of brand attitude. Oftentimes, implicit and explicit measures can diverge. What is perplexing, in this case, is that while there was greater detection of the false advertising information in the positive mood condition, there was also more favorable response toward the advertised brand, as evidenced by the IAT. From the verbal protocols, it seemed that those 
who detected didn't like the advertising very much (our next experiment will provide a measure for this). In her research on consumers' response to potentially manipulating ads, Campbell (1995) posits that the consumer does a cost/benefit analysis-in this instance, perhaps weighing the positive feelings they may get from viewing the ad (i.e., entertainment value) over the negative feelings associated with noticing the falsity. The autobiographical ad allowed the participants to journey into their childhood memories, and thus provided some positive entertainment value that may have overwhelmed any feelings associated with noticing that the ad tried to mislead them.

We thus manipulate the executional style of the advertising in Experiment 2. Wegener, Petty, and Smith (1995) proposed a hedonic contingency view of mood and message processing where they find that if the context is hedonic, those in a positive mood will scrutinize a message more elaboratively. Isen and her colleagues also argue that when the task at hand is interesting or important, positive mood promotes careful, thorough, open-minded, and greater systematic processing (Ashby, Isen, and Turken 1999). Therefore, the following hypothesis is developed:

Hypothesis 3: Positive mood will lead to deeper processing of the false advertising to a greater degree when the context is hedonic, and this will result in greater detection and less acceptance of the false information in judgments.

\section{Experiment 2}

To better understand how mood state interacts with the processing of the false advertising information, we vary the type of advertising received in this study-autobiographical versus informational. Past research (Obermiller, Spangenberg, and MacLachlan 2005) finds that emotional appeals fare better than informational ones with ad skeptics. Emotional, autobiographical advertising has been found to be related to positive affect toward the brand (Baumgartner, Sujan, and Bettman 1992). The question we seek to answer is this: Does this more hedonic emotional ad lead to more detection in the positive mood, or are those in the positive mood just overall better processors (i.e., detection would occur in spite of the advertising execution)? In addition, we are interested in whether the mood/affect transfer occurs only with the autobiographical ad (which cues favorable memories and associations) or whether the mood-induction video might result in an overall halo effect for the advertised brand. Might, as others have found the autobiographical ad also result in overall affect transfer to the brand as well? To generalize our findings, we focus on a different brand, Wendy's. One 
could argue that the Disney brand is itself "hedonic," and therefore our findings might not occur with another brand.

\section{Method}

Participants

One hundred fifty ( 82 female, 68 male) undergraduates participated in this experiment in exchange for course credit.

Design

This was a 3 mood (positive, neutral, negative) $\times 2$ ad (informational, autobiographical) between-subjects design. Participants were randomly assigned to one of the six conditions.

Stimuli

Two print ads were developed for this study-an informational ad and an autobiographical ad. Both featured a false image of a Playland in the center next to a Wendy's restaurant, had a picture of Dave Thomas at the bottom, and had a picture of a child eating a hamburger at the center right. The same colors and fonts were used in both ads. What differed between the ads was the main copy. The autobiographical ad read: "REMEMBER YOUR CHILDHOOD VISITS TO WENDY'S? Weekly rituals with your family to enjoy tasty fries and burgers...No worries...Just simple fun...Playing on the slide...Jumping in the ball pit...Swinging on the swing sets...COME BACK AND RELIVE THOSE MEMORIES." The informational ad read: "FREE FROSTY WEEKEND! Wendy's restaurants are offering free small Frosties to all paying customers this weekend only. Customers are encouraged to bring their children and entertain them in the play areas with swings, ball pics and slides. GET A FREE FROSTY!"

Note that both ads contained the same number of words. The informational ad was written in the third person and did not directly reference the reader or their memories (as per Escalas 2007). Both ads featured a false image of a Playland (Wendy's restaurants do not have that feature) and both make false mention of swings, ball pits, and slides in the text.

\section{Procedure}

Participants came to the study and immediately were shown one of the mood induction videos (the same used in Experiment 1). Following that video, they were asked to indicate their current mood (on the same mood scales used earlier). Immediately thereafter they were presented the Wendy's ad 
and were asked to write down their thoughts about the ad. An attitude-toward-the-ad-scale was added to assess how they felt about the ad. Next, they participated in a live-minute distraction task.

Participants proceeded to the computer task where they were given the same instructions for the IAT as in the earlier experiment. The same positive and negative words used in the prior experiment were used here. What differed was the brand used in this task: Wendy's versus other fast food. The task included eight images associated with Wendy's (Dave Thomas, the "Where's the Beef woman, the Wendy's sign, Wendy's chicken nuggets, Wendy's square-shaped burger, a neon Wendy's sign, Wendy's late-night logo, Wendy's ad, and a Wendy's drink) and eight images associated with other fast-food restaurants (Colonel Sanders, McDonald's arches, Ronald McDonald, "Jack" from Jack in the Box, the Burger King character, the Taco Bell sign, the In-N-Out sign, and the Hardee's logo). A picture of a child sliding down a slide into a ball pit was incorporated into the categorization task to determine whether the false information became incorporated into the Wendy's category in judgments.

\section{Measures}

The same four mood manipulation scales were used to assess mood state after viewing the video (and these were combined to form an index, Cronbach's $(\alpha=.87$ ). Participants wrote down their thoughts about the ad and these were coded for number of words, whether or not they referenced the false information (i.e., were a detector) and the type of processing strategy they appeared to take (relational, item-specific, both, or superficial). Their attitude toward the ad was assessed by having them rate on 10-point scales whether the ad was unfavorable/favorable, bad/good, unpleasant/pleasant, and negative/positive. These scales were highly related (Cronbach's $\alpha .93$ ) and were combined to form an attitude-toward-the-ad index.

The acceptance of the false information was measured by counting how many times the participant classified the image of the child on the slide/in the ball pit in a Playland as being part of the Wendy's category. The IAT was computed as before, with the critical conditions subtracted from one another (where a positive score indicates more positive associations).

\section{$\underline{\text { Results }}$}

\section{Mood Manipulation Check}

The mood manipulation check was given right after the video and was found to be significant. Using general linear model (GLM) with mood, ad, and the interaction as factors, only mood was a significant factor, $F(2,36)=130, p<.0001$. Means follow: positive/autobiographical, $M=6$; positive/ 
informational, $M=6$; neutral/autobiographical, $M=4.1$; neutral/informational, $M=4.2$;

negative/autobiographical, $M=3.1$; negative/informational, $M=2.9$ -

\section{Advertising Response}

The free response to the advertising was analyzed by looking at the number of words, the type of processing used, and whether or not the participant indicated he or she noticed that Wendy's does not (or never had) Playland areas. Based on Hypothesis 3, our primary focus is on the positive mood participants. Participants who saw the positive mood induction video had more to say about the ad than those who saw the other mood-inducing videos, resulting in significantly longer responses; mood was the only significant factor, $F(2,139)=324, p=.05$ (see middle of Table I).

The most flexible processing strategy is that which uses both relational and item-specific processing. Participants in the positive mood condition were more likely to use both item specific and relational processing than those in other mood-inducing conditions, $\chi^{2}(n=150)=29-26, p<.0001$, but this was driven by the amount of relational processing encouraged by the autobiographical ad. For participants who received the autobiographical ad, mood made a big difference: $42 \%$ in positive employed both types of processing strategies, compared to $6 \%$ neutral and $6 \%$ negative, $\chi^{2}(n=75)=$ $37.5, p<0001$. There were no significant differences between mood groups in terms of using both processing strategies when having received the informational ad, positive $8 \%$, neutral $8 \%$ and negative $\chi^{2}<1$. This therefore supports Hypothesis 3 , the hedonic context view of positive mood: Only when the advertisement was emotional and had higher entertainment value was there more extensive processing of the advertising information. The autobiographical ad encouraged more relational processing overall than the informational ad, $52 \%$ vs. $14 \%$ significantly different at $\chi^{2}(n=150)=23.52, p<.0001$; however, only participants in the positive mood condition were able to use both the relational processing encouraged by this ad execution and their item-specific processing of the ad to notice the falsity.

For detection of the false information, mood was an overall significant factor, $\chi^{2}(n=150)=14.9$, $p=006$, where participants who received the positive mood induction were more likely to detect the falsity than those in the other mood-induced conditions, but this again was driven by the autobiographical advertising (where $68 \%$ positive compared to $16 \%$ neutral and $12 \%$ negative detected, significant at $\left.\chi^{2}(n=75)=22.4, p<.0001\right)$. There were no significant differences in detection in the informational conditions.

Participants who detected the false information in the ad reported lower attitudes toward the ad than those who did not: $M=4.8$ versus $M=6.3$, significantly different at $t(148)=4.48, p<.0001$. This 
was primarily driven by the positive mood group that saw the autobiographical ad. The mean in that group ( $M=4.5$ ) was found to be significantly lower than the other conditions. It is interesting to note that those who detected reported higher affect toward Wendy's on the IAT, $M=267$ ms versus $165 \mathrm{~ms}$, $t(148)=2.84, p<.01$.

\section{Acceptance of the False Information}

We expected an interaction, given the greater detection in the positive mood/autobiographical condition, where those in the positive mood condition receiving the autobiographical ad would have the lowest acceptance rates. The interaction was significant at $p=.1$ (but not the more accepted level of $p=.05), F(2,149)=2.3, p=1$. Both main effects were significant-type of advertising, $F(1,149)=9.7 p<.01$, and mood, $F(2,149)=7.77, p<.001$ - but they were qualified by the interaction (see Table 2 for the means). Given Hypothesis 3, a one-tail comparison between the positive autobiographical and positive informational group was warranted, and that contrast was found to be significant below $p<.05$, which supports Hypothesis 3.

Implicit Association Test

There was a mood-congruent effect on the IAT, where participants in the positive mood condition had larger positive scores than those in the negative or neutral mood conditions, $F(2$, 149) $=36.36, p<.0001$ (see Table 2). There was also a main effect of ad, where participants in the autobiographical conditions had a more positive IAT effect than those in the other conditions, F (1, $149)=2.65, p=.10$. Therefore, affect transfer can occur both through the mood environment and through affect created through an autobiographical advertisement. This occurs independently of the amount of detection or negative feelings incurred at ad exposure.

\section{Relationship between Measures}

The best predictor of whether one would accept and integrate the false information in categorization judgments continued to be whether or not he or she detected the falsity at encoding, $r=-$ .51 , and the best indicator of whether one would detect is whether or not they employed both types of processing, $r=.54$. The IAT and the self-report attitude toward the ad were negatively related, $r=-.26$, while the detection and IAT were positively related, $r=.22$. These effects were primarily due to participants in the positive mood condition who viewed the autobiographical ad. They noticed the false 
information more often and reported negative feelings toward the ad, but at the time of the IAT, the positive memories that the mood-inducing video and ad conjured up drove their implicit attitude.

\section{Discussion}

The purpose of this study was to determine whether consumers in a positive mood are only able to deeply process and detect the false information more often (than those in other mood states) if it is presented in a hedonic advertisement. We found that to be the case, consistent with Hypothesis 3, the hedonic contingency view.

A curious finding in both experiments is that while those in a positive mood are more likely to notice the false information and they report liking the ad less, these ad-related thoughts are not at all taken into account on the implicit measure of brand attitude. While this finding is consistent with psychological research on the disassociation between explicit and implicit measures (see Schacter 1996), it is contrary to research on consumer skepticism, which suggests that there is "payback" to those who try to mislead consumers through their advertising claims (see Obermiller, Spangenberg, and MacLachlan 2005). That latter view is built on the following premises: Consumers are becoming increasingly skeptical of advertising overall, and particularly when ads make claims that are inherently false (Friestad and Wright 1994). If consumers perceive an advertisement is raise, they may discount the message entirely, or they may increase their counterarguments to the ad (Petty, Ostrom, and Brock 1981). Either way, if an advertisement is perceived as being manipulative, it will result in low attitudes toward the ad, as well as more negative feelings about the brand overall (Lutz 1985). Increased skepticism should lead to immediate responses to the ads, making consumers like the ads less and finding the claims less informative (Obermiller, Spangenberg, and MacLachlan 2005).

As a means to reconcile our findings with the consumer skepticism literature, we introduce the synapse view of memory. The negative feelings about the brand and its attempt to mislead with the false information were accessible momentarily, but consumers' positive feelings about their own past (made more so through the mood-induction video) led to more reliance on this personal memory, a more chronic type of accessible information (Johar, Moreau, and Schwarz 2003). In other words, the false ad made them reel temporarily bad, but in the long run, the emotional autobiographical memory cued by the advertising and the mood context made them feel good (see Figure 1).

Although implicit measures have been thought to be more enduring than explicit ones (Lee 2002), even implicit attitudes have been found to be shaped by recent orienting experiences (Dasgupta and Greenwald 2001). Because there was a 20-minure delay between exposure to the false advertising 
and the implicit measure of feelings about the brand (IAT), it is possible that any negative feelings associated with viewing the false ad decayed (at a faster rate) than the positive feelings elicited while viewing the autobiographical ad and through the mood induction. This is consistent with the synapse model of memory proposed by Higgins, Bargh, and Lombardi (1985). According to this model of memory, "Decay over time of the excitation level of a construct following its last activation is slower when the construct has been frequently activated than when it has been activated only once" (Higgins 1989, p. 86).

Hypothesis 4: Participants who notice the false advertising information will have negative feelings associated with that detection, which influences how they feel about the brand at that moment, but over time, those once activated negative feelings associated with noticing the falsity decay at a faster rate and their own personal feelings and associations become more influential in their implicit brand judgments.

\section{Experiment 3}

In this experiment, we vary the timing of the IAT and advertising response for participants in the positive mood condition receiving the false autobiographical Wendy's ad. This study has both theoretical and practical import to advertising researchers: Theoretically, it may demonstrate that moods impact on advertising susceptibility can have both implicit and explicit reactions that are separate, and practically, it calls into question when consumer attitudes toward advertising should be collected. We predict that if the IAT is taken immediately after exposure to the false ad, there will be less positive feelings toward the advertised brand on that implicit measure than with a time delay. We also predict that there will be less detection if there is a delay between ad exposure and advertising response, and therefore more acceptance of the false information in the integration task. Both predictions are consistent with the synapse model of memory (our Hypothesis 4).

\section{Method}

Participants

Ninety-six undergraduates (45 female, 51 male) participated in this experiment in exchange for course credit. 


\section{Procedure}

The same basic procedure was followed for this experiment as the previous experiments, except that we added a delay either between ad exposure and response, or ad exposure and IAT. This resulted in four cells: one where both the ad response and IAT occurred immediately after exposure to the false Wendy's ad; one where the ad response was immediate but IAT delayed (20 minutes, as in our other experiments); another where the IAT was immediate but ad response delayed; and the last where both the IAT and ad response were delayed. The same false autobiographical ad used in Experiment 2 was used here, as that led to the most detection but also favorable feelings toward the advertised brand, thus representing an interesting paradox for investigation.

FIGURE 1

Conceptual Model

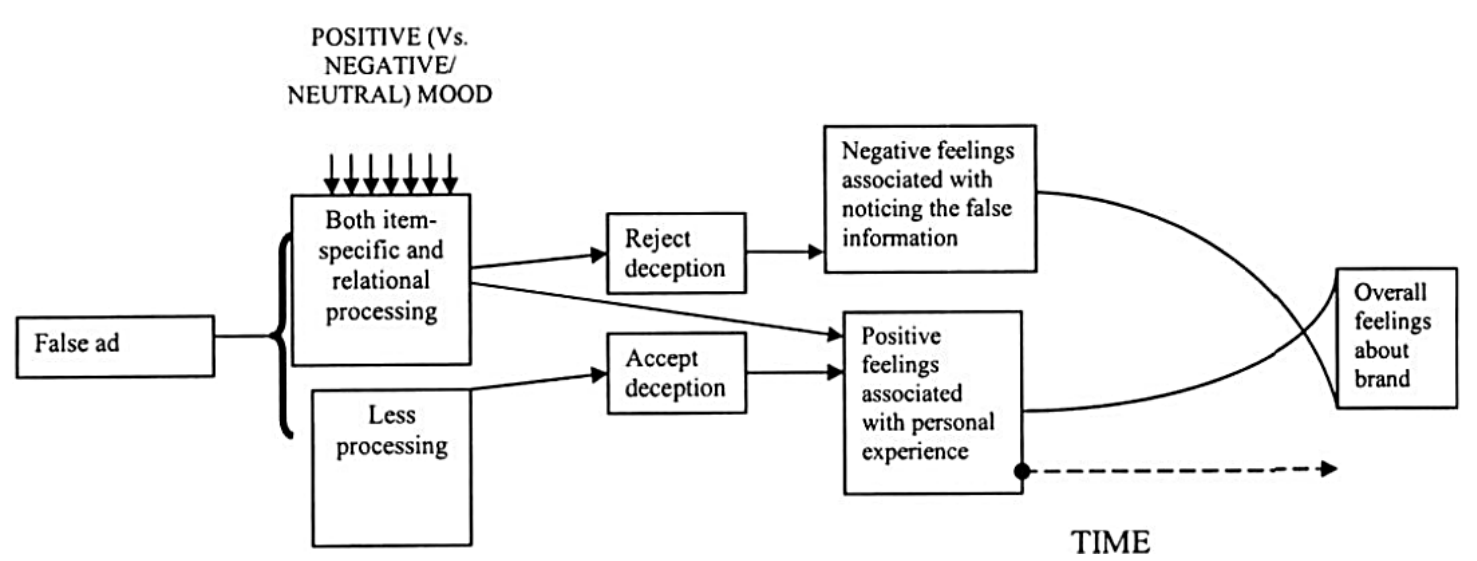

Measures

After the positive mood-inducing video, mood was checked via the scale used in the previous studies, and there was no difference across conditions (to be expected). As in the previous studies, ad response was measured by recording the number of words and coding for the processing strategy indicated in the response (superficial, item-specific, relational, or both). Coders also indicated whether or not detection of the false Playland reference occurred in the advertising response. The same fourscale attitude toward the ad as used in Experiment 2 was used (Cronbach's $\alpha=.93$ ).

The Wendy's/other IAT was the computer task (same version as in Experiment 2), and within the categorization task, there was the image of the child in a Playland (sliding into a ball pit). At the very end of the session, two measures were added to assess participants' feelings about their childhood memories, as well as about the false advertising: "In this study you saw an advertisement for Wendy's asking you to remember positive experiences at their restaurants. How positive would you rate your 
own childhood visits to Wendy's?'" (anchored by 1=negative, 7=positive). "In this ad, Wendy's featured a Playland, which is actually a McDonald's feature, in order to make you feel a more favorable connection to their restaurants. How does this deception make you feel?" (anchored by 1=negative, 7=positive).

\section{$\underline{\text { Results }}$}

Response to the Advertising

There was no difference across conditions in terms of the amount written about the advertisement, $M=31$ words. There was a difference in the processing strategy employed, where those who wrote their responses to the ad immediately on viewing were more likely to employ both relational and item-specific processing: $71 \%$ versus $19 \%, \chi^{2}(n=95)=26.07, p<.0001$ (see Table 1 for the means). The "both" strategy indicates more flexible processing, and this led to more detection in the ad response immediate conditions. Delay was the only significant factor, $65 \%$ versus $25 \%, \chi^{2}(n=95)=14.9, p<.0001$. The detection also resulted in less favorable feelings reported about the ad in the immediate (compared to delayed) ad response conditions: $M=5.8$ versus $M=5.0, t(93)=1.87, p<.05$.

\section{Acceptance of the False Information}

Because of the lower levels of detection of the false information where ad response was delayed, it was expected that there would be more integration of the false Playland information in their categorization judgments, and that was found: $M=1.9$ versus $M=2.9, t(93)=1.75, p<.05$ (see Table 2).

\section{Implicit Association Test}

In the previous studies, the IAT was delayed after response to the false advertising and there was a disconnect between the negative feelings associated with noticing the falsity and the feelings toward the brand. Consistent with the synapse model of memory (Higgins 1989; our Hypothesis 4) and with findings in social psychology on context effects, we expected that the IAT effect would be diminished if the negative feelings toward the ad were available in working memory. This was found to be the case, as there was a lower IAT when taken immediately after ad viewing than if delayed: $M=107$ ms versus $M=276 \mathrm{~ms}, t(91)=5.14, p<.0001$ (see Table 2 ).

When the IAT was delayed, participants felt more positive about the ad falsity, $M=3.31$ versus $M=2.57, t(91)=2.2, p<.05$, and participants also reported having more favorable childhood memories of Wendy's in the delay, $M=4.98$ versus $M=4.3$ immediate, significantly different at $t(92)=1.87, p<.05$. This suggests, as the synapse model proposes, that when time has passed between the false advertising 
exposure and judgment, individuals rely more on their past favorable memory and express less negativity about the potential deception.

\section{Discussion}

This experiment provided more insight into why participants in the positive mood condition, who were more likely to notice the false information, did not transfer the negative feelings associated with detection to the advertised brand. The synapse view of memory states that episodic information viewed once (the false ad information) decays at a faster rate than consequential personal information (childhood memories and feelings cued by the ad and the mood induction video). When there was a short delay between the ad viewing and written response (to clear working memory), detection of the false information decreased substantially and was accompanied by more acceptance of the false information in the categorization task. Meanwhile, if the implicit association measure was taken when those negative feelings regarding false information were active in working memory, there were less favorable attitudes reported on the IAT (which is consistent with the lower attitude-toward-the-ad measure).

\section{General Discussion}

The purpose of this research investigation was to determine whether mood state would increase susceptibility to false advertising information. We found that mood had both explicit and implicit effects on reactions to the false advertising. In all studies, the more explicit effects of the detection of false advertising information were heightened in the positive mood, and this was due to a more flexible processing strategy that allowed consumers to compare in working memory the advertising and past personal experiences (using both item-specific and relational processing). Experiment 2 further found that an emotional/autobiographical ad execution can increase this detection while also promoting the more implicit positive feelings toward the advertised brand (for those in a positive mood). The synapse model of memory was proposed to account for these paradoxical findings, as the false information (and feelings about potential deception) decayed at a faster rate than the personal memories that were related to implicit attitudes toward the brand. When the implicit test was taken right after exposure to the false ad (and those negative feelings were accessible), the implicit attitude expressed toward the brand was much lower than if time transpired, allowing the favorable associations to come back into play. 
This research has implications for those who study mood and advertising persuasion; more generally, the results have implications tor social policy on deceptive advertising. These implications, as well as future research and limitations, are discussed below.

\section{Mood and Persuasion}

We started our paper with a quote from a prominent social psychologist that suggests advertising persuasion best occurs in a positive mood. Our research investigation was guided toward understanding how positive mood can influence consumers' response to advertising. We found that positive mood can have both explicit effects (which influence the processing of the ad) and implicit effects (whereby the consumer's mood transfers to the advertised brand). Because we found a disassociation in our measures (where those who detected and disliked the ad still showed positive feelings to the brand), we believe that advertising researchers, rather than considering positive mood as having an either/or outcome for ad response, incorporate measures that acknowledge the different layers of influence.

Our research continues down the stream of showing that positive mood can enhance rather than detract from consumer processing. Very young and very old consumers had been the focal concern of those who study susceptibility to advertising (mainly deception). While these individual differences are quite important and have social policy ramifications, what has been overlooked in the past is how situational factors may attenuate the results. Media context is a decision advertisers routinely make, and knowing that their advertising may be less likely to be elaborated on in either a neutral or negative mood context may cause the less scrupulous advertisers to seek out those contexts. These results also have more general implications. For instance, if an advertiser wanted their ad processed because they have a real point of difference, then using an emotional ad in a positive mood context would be best so that consumers would process the ads more deeply.

\section{$\underline{\text { Advertising Deception and Social Policy }}$}

We note that in our research we studied false advertising, which is different from deceptive advertising (though related). For an advertisement to be categorized as deceptive, it must have the potential to result in material harm to the consumer. Whether or not coming to believe Bugs Bunny is a Disney character or that Wendy's had Playlands after receiving our ads is material and causes harm to die consumer is not tor us to debate (though we do note that competitive brands could be harmed in such a case). Both types of false information were very prominent in the advertisements and future 
research might consider manipulating an element that could be directly construed as being harmful to the consumer. What is of relevance to the deceptive advertising literature has to do with our measures, particularly with respect to the timing of advertising response.

What had seemed to be a positive trend in thwarting deceptive advertising was the increased observance of ad skepticism among consumers (Obermiller, Spangenberg, and MacLachlan 2005). However, studies demonstrating skepticism have looked solely at consumers' perceptions of advertising at exposure. The synapse model of memory presents a dim prospect for social policy on deceptive advertising. People may come to believe what they initially regarded as unbelievable (Gilbert, Krull, and Malone 1990). In the present research, we found that even those consumers who were "skeptical" about the ad claims and noticed the falsity at exposure were still positively influenced by the advertising message just 20 minutes later on implicit measures. Therefore, all an unscrupulous marketer would need to do is to "mask" their misleading material in the form of an emotionally engaging ad-even if consumers were to notice such falsity, over time what they will remember and feel about the brand is more driven by the personal response to the ad execution than by the validity of the ad content.

\section{Limitations and Future Research}

The majority of program-induced mood experiments have employed programs that would be considered "humorous" such as ours, which featured Jim Carrey and Bill Cosby. Although humor and comedy are typical of most prime-time programming in which ads are placed, it could be that in the present studies, the humor itself "primed" participants to notice discrepancy more so than had we, for example, induced positive mood with a gift. Also, while mood is an important situational variable, there potentially are others that also may inhibit or enhance susceptibility, such as time distraction, stress, time of day (circadian rhythms). Research in that direction could potentially identify more about the suggestion process, such as the role of imagery, creativity, and other factors. While this research investigation proposes that deceptive advertising researchers more fully investigate those types of contextual variables, we in no way want to imply that individual differences in susceptibility should be diminished, nor should the importance of finding measures that correlate with susceptibility. We note that our sample consisted of undergraduates in their twenties; future research ought to consider other age groups. 


\section{References}

Arndt, Jason, and Lynne M. Reder (2003), "The Effects of Distinctive Visual Information on False Recognition," Journal of Memory and Language, 48(1), 1-15.

Ashby, E Gregory, Alice M. Isen, and And U. Turken (1999), "A Neuropsychological Theory of Positive Affect and Its Influence on Cognition," Psychological Review: 106 (3), 529-550.

Aylesworth, Andrew B., and Scott B. MacKenzie (1998), "Context Is Key: The Effect of Program-Induced Mood on Thoughts About the Ad," Journal of Advertising, 27 (2), 17-31.

Batra, Rajeev, and Douglas M. Stayman (1990), "The Role of Mood in Advertising Effectiveness," Journal of Consumer Research, 17 (September), 203-214.

Baumgartner, Hans, Mita Sujan, and James R. Bettman (1992), "Autobiographical Memories, Affect and Consumer Information Processing," Journal of Consumer Psychology. 1(1), 53-82.

Bless, Herbert, Gerd Bohner, Norbert Schwarz, and Fritz Strack (1990), "Mood and Persuasion: A Cognitive Response Theory," Personality and Social Psychology Bulletin, 16 (June), 331-345.

—. Gerald L. Clore, Norbert Schwarz, Verena Golisano, Christina Rabe, and Marcus Wölk (1996), "Mood and the Use of Scripts: Does Being in a Happy Mood Really Lead to Mindlessness?" Journal of Personality and Social Psychology. 71 (4), 665-679.

Braun, Kathryn A. (1999). "Post-Experience Advertising Effects on Consumer Memory/'Journal of Consumer Research, 25 (March), 319-334. , and Elizabeth F. Loftus (1998), "Advertising's Misinformation Effect." Applied Cognitive Psychology. 12 (December), 569-591.

—, Rhiannon Ellis, and Elizabeth E Loftus (2001), "Make My Memory: How Advertising Can Change Our Memories or the Past," Psychology and Marketing, 19 (January), 1-23-

Braun-LaTour, Kathryn A., Melissa Grinley, and Elizabeth F. Loftus (2006), "Tourist Memory Distortion," Journal of Travel Research. 44 (4), 360-367.

, Michael S. LaTour, Jacqueline Pickrell, and Elizabeth F. Loftus (2001), "How and When Advertising Can Influence Memory for Consumer Experience," Journal of Advertising, 33 (4), 726.

Brunel, Frederic F., Brian C. Tietje, and Anthony G. Greenwald (2004), "Is the Implicit Association Test a Valid and Valuable Measure or Implicit Consumer Social Cognition?" Journal of Consumer Psychology, 14 (4), 385-404. 
Campbell, Margaret (1995), "When Attention-Getting Advertising Tactics Elicit Consumer Inferences of Manipulative Intent: The Importance of Balancing Benefits and Investments," Journal of Consumer Psychology, 4 (3), 335-354.

Dasgupta, Nilanjana, and Anthony G. Greenwald (2001), "On die Malleability of Automatic Attitudes: Combating Automatic Prejudice with Images of Admired and Disliked Individuals," Journal of Personality and Social Psychology, 81 (5), 800-814.

Escalas, Jennifer Edson (2007), "Narrative Versus Analytical Self- Referencing and Persuasion," Journal of Consumer Research. 34 (March), 421-429.

Estrada, Carlos A., Alice M. Isen, and Mark J. Young (1997), "Positive Affect Facilitates Integration of Information and Decreases Anchoring in Reasoning Among Physicians," Organizational Behavior and Human Decision Processes. 72 (October), 117-135.

Eysenck, Hans J., William J. Arnold, and Richard Meili (1975), Encyclopedia of Psychology, vol. 2, Bungay, Suffolk: Fontana.

Filopowicz, Allan (2000), "The Effect of Humor on Individual and Group Task Performance," Harvard University.

Forgas, Joseph (2001), "The Affect Infusion Model: An Integrative Theory of Mood Effects on Cognition and Judgments," in Theories of Mood and Cognition: A User's Guidebook. Leonard L. Martin and Gerald L. Clore, eds., Mahwah, NJ: Lawrence Erlbaum, 99-134.

Friestad, Marian, and Peter Wright (1994), "The Persuasion Knowledge Model: How People Cope with Persuasion Attempts, "Journal of Consumer Research, 21 (June), L-31.

Gibson, Brian (2008), "Can Evaluative Conditioning Change Attitudes Toward Mature Brands? New Evidence from the Implicit Association Test, "Journal of Consumer Research, 35 (I), 178-188.

Gilbert, Daniel T. (1991), "How Mental Systems Believe," American Psychologist. 46, 107-119.

—, Douglas S. Krull, and Patrick S. Malone (1990), "Unbelieving the Unbelievable: Some Problems in the Rejection of False Information," Journal of Personality and Social Psychology. 59 (4), $601-$ $613-$

Goldberg, Marvin E., and Gerald J. Gorn (1987), "Happy and Sad TV Programs: How They Affect Reactions to Commercials," Journal of Consumer Research. 14, 387-402.

Greenwald, Anthony G., and Mahzarin R. Banaji (1995). "Implicit Social Cognition: Attitudes. SelfEsteem, and Stereotypes," Psychological Review. 102 (January), 4-27. , and Brian A. Nosek (2001), "Health of the Implicit Attitude Test at Age Three," Zeitschrift fur Experimentally Psychologie 48, 85-93 (in German). 
—, Debbie E. McGhee, and Jordan L. K. Schwartz (1998), "Measuring Individual Differences in Implicit Cognition: The Implicit Association Test," Journal of Personality and Social Psychology, 7$1(6), 1$ (64-1480.

Higgins, E. Tory (1989), "Knowledge Accessibility and Activation: Subjectivity and Suffering from Unconscious Sources," in Unintended Thought, John A. Bargh and James S. Uleman, eds., New York: Guilford Press, 75-123.

_ John A. Bargh, and Wendy Lombard! (1985), "The Nature of Priming Effects on Categorization," Journal of Experimental Psychology: [warning. Memory and Cognition. 11, 59-69.

Isen, Alice M. (1984), "Toward Understanding the Role of Affect in Cognition," in Handbook of Social Cognition. Robert S. Wyer and Thomas K. Srull, eds., Hillsdale, NJ: Lawrence Erlbaum, 179-236. (1993), "Positive Affect and Decision Making," in Handbook of Emotions. Michael Lewis and Jeanette M. Haviland, eds., New York: Guilford, 261-277. .and Kimberly A. Daub man (1984). "The Influence of Affect on Categorization/' Journal of Personality and Social Psychology. 47 (6), 1206-1217.

— Journal of Personality and Social Psychology, 52 (6), 1122-1131.

Johar, Gita Venkataramani (1995), "Consumer Involvement and Deception from Implied Advertising Claims," Journal of Marketing Research. 32 (August), 267-279.

_ Page Moreau, and Norbert Schwarz (2003), "Gender Typed Advertisements and Impression Formation: The Role of Chronic and Temporary Accessibility" Journal of Consumer Psychology. 13 (3), 220-229-

Kamins, Michael A., Lawrence J. Marks, and Deborah Skinner 099I)> "Television Commercial Evaluation in the Context of Program Induced Mood: Congruency Versus Consistency Effects, "Journal of Advertising. 20 (June), $1-14$.

Kuykendall, David, and John P. Keating (1990), "Mood and Persuasion: Evidence for the Differential Influence of Positive and Negative States," Psychology and Marketing. 7(1), 1-9.

Lee, Angela Y. (2002), "Effects of Implicit Memory on Memory- Based Versus Stimulus-Based Brand Choice, Journal of Marketing Research. 39 (November), 440-454.

_ and Brian Sternthal (1999), "The Effects of Positive Mood on Memory," Journal of Consumer Research. 26 (September), 115-127.

Loftus, Elizabeth R (1979), "Reactions to Blatantly Contradictory Information," Memory and Cognition. 1 (5), 368-374. 
Lord, Kenneth R., and Chung K. Kim (1995), "Inoculating Consumers Against Deception: The Influence of Framing and Executional Style," Journal of Consumer Polity 18 (1), 1-23.

Lutz, Richard J. (1985), "Affective and Cognitive Antecedents of Attitude Toward the Ad: A Conceptual Framework," in Psychological Processes and Advertising Effects, Linda Alwitt and Andrew Mitchell, eds., Hillsdale. NJ: Lawrence Erlbaum, 45-65.

Mackie, Diane M., and Leila T. Worth (1989), "Processing Deficits and the Mediation of Positive Affect in Persuasion," Journal of Personality and Social Psychology. 57(1), 27-40.

Maison, Dominika, Anthony G. Greenwald, and Ralph Bruin (2001), "The Implicit Association Test as a Measure of Implicit Consumer Attitudes." Polish Psychological Bulletin. 23, 1-9.

Mathur, Mahima, and Amitava Chattopadhyay (1991), 'The Impact of Moods Generated by Television Programs on Responses to Advertising," Psychology1 and Marketing. 8(1), 59-77.

McGuire, William J. (1985), "Attitudes and Attitude Change," in The Handbook of Social Psychology. Gardner Lindzey and Elliot Aronson, eds., New York: Random House, 233-346.

Murray, Noel, Harish Sujan, Edward R. Hirt, and Mita Sujan (1990), "The Influence of Mood on Categorization: A Cognitive Flexibility Interpretation," Journal of Personality and Social Psychology. 59 (September), 411-425.

Obermiller, Carl, Eric Spangenberg, and Douglas L. MacLachlan (2005), "Ad Skepticism: The Consequences of Disbelief," Journal of Advertising. 34 (3), 7-17.

Olson, Jerry C., and Phillip A. Dover (1978), "Cognitive Effects of Deceptive Advertising," Journal of Marketing Research. 15(1), 29-38.

Peterson, Robert A., and Matthew Sauber (1983). "A Mood Scale for Survey Research," in American Marketing Association Educators Proceedings. Patrick Murphy, ed., Chicago: American Marketing Association, 409-414.

Petty, Richard E., Thomas M. Ostrom, and Timothy C. Brock (1981), "Historical Foundations of the Cognitive Response Approach to Attitudes and Persuasion," in Cognitive Responses in Persuasion. Richard E. Petty, Thomas M. Ostrom, and Timothy C. Brock, eds., Hillsdale, NJ: Lawrence Erlbaum, 5-29-

—, David W. Schumann, Stephen A. Richman, and Alan J. Strathman (1993), "Positive Mood and Persuasion: Different Roles for Affect Under High- and Low-Elaboration Conditions," Journal of Personality arid Social Psychology. 64, 5-20.

Puccinelli, Nancy M. (2000), "Errors in Mood Regulation: Do We Know What's Best for Us?" College of Business Administration. Northeastern University. 
Schacter, Daniel (1996), Searching for Memory. New York: BasicBooks.

Schumaker, John F. (1991), "Introduction," in Human Suggestibility: Advances in Theory, Research and Application.)John F. Schumaker, ed., New York: Routledge.

Schwarz, Norbert, and Herbert Bless (1991), "Happy and Mindless, but Sad and Smart? The Impact of Affective States on Analytic Reasoning," in Emotion and Social Judgments, vol. 23 of International Series in Experimental Social Psychology. Joseph P. Forgas, ed., Oxford: Pergamon Press, 55-71.

Shapiro, Stewart, and H. Shanker Krishnan (2001), "Memory- Based Measures for Assessing Advertising Effects: A Comparison of Explicit and Implicit Memory Effects." Journal of Advertising, 30 (Fall), $1-13$.

Skurnik, lan. Carolyn Y(x>n, Denise C. Park, and Norbert Schwarz (2005), "How Warnings About False Claims Become Recommendations," Journal of Consumer Research, 31 (4), 713-724.

Stayman, Douglas M., and Rajeev Batra (1991), "Encoding and Retrieval of Ad Affect in Memory." Journal of Marketing Research. 28 (May), 232-239.

Tousignant, James P., David Hall, and Elizabeth F. Loftus (1986), "Discrepancy Detection and Vulnerability to Misleading Postevent Information," Memory and Cognition. 14 (4), 329-338. Wegener, Duane T, Richard E. Petty, and Stephen M. Smith (1995), "Positive Mood Can Increase or Decrease Message Scrutiny: The Hedonic Contingency View of Mood and Message Processing, "Journal of Personality and Social Psychology. 69 (July), 5-15.

Worth, Leila T., and Diane M. Mackie (1987), "Cognitive Mediation of Positive Affect in Persuasion," Social Cognition. 5(1), 76-94.

Zaltman, Gerald (2003), How Customers Think: Essential Insights into the Mind of the Market. Boston: Harvard Business School Press.

\footnotetext{
${ }^{1}$ Two reviewers raised the concern that Liar, Liar may have primed participants in the positive mood condition to notice the false information more (rather than the effect driven by mood). We therefore ran a condition where participants saw the same Bill Cosby clip but with a new Jim Carrey clip from the movie Ace Ventura. We pretested this new arrangement on 24 participants and found it to elicit the same level of positive affect as the original positive mood induction video $(M=5.6)$. We then ran the same procedure with this new sequence and found results parallel to our original positive sequence: The mood manipulation measure was $5.7,61 \%$ were Bugs detectors, they wrote an average of 53 words, $61 \%$ used the "both" processing strategy, there was an average of 1.3 incorrect Bugs Bunny errors in categorization, and the I AT was 356. Because these results were not significantly different from the original sequence, we feel confident that it is the positive mood that is driving the effects and that our original sequence is an appropriate mood induction.

${ }^{2}$ One reviewer questioned whether the neutral mood condition was the same as a "no mood" condition. The rationale for having the mood induction is that it "evens" out the participants. For instance, a person could come in with a very positive mood (because they just fell in love) or they could come in with a negative mood (after receiving a bad grade). We ran a condition that received the false Bugs Bunny ad without a mood induction and
} 
found that their mood was higher than the neutral but not as high as the positive mood group, $M=4.9$. There were three participants in the group (out of 14) who detected the false Bugs information, and these were all those who came in at a more positive mood $(M=5.2)$; these participants used a "both" processing strategy. The IAT was a bit higher than the neutral condition, but not as high as the positive mood group ( $M=331 \mathrm{~ms}$ ). 